\title{
Exploring "Intersectoral Collaboration" towards the Integration of Indigenous Knowledge into Adult Education Programs in North Wollo, Ethiopia
}

\author{
Yalalem Assefa \\ Department of Adult Education and Community Development, Woldia University, P.O. Box: 400, Woldia, Ethiopia \\ Correspondence should be addressed to Yalalem Assefa; yalalem2012@gmail.com
}

Received 25 August 2021; Revised 16 December 2021; Accepted 18 December 2021; Published 3 January 2022

Academic Editor: Ehsan Namaziandost

Copyright (c) 2022 Yalalem Assefa. This is an open access article distributed under the Creative Commons Attribution License, which permits unrestricted use, distribution, and reproduction in any medium, provided the original work is properly cited.

\begin{abstract}
Integration of indigenous knowledge into adult education recognizes collaboration based on indigenous frameworks and methodologies and gives more attention to people's history, politics, cultural beliefs, and philosophical views. The most important beginning phases and tasks in promoting indigenous-based learning are establishing a responsive organizational structure that helps to identify and agree on what roles and responsibilities are played by each concerned stakeholder. Considering this in mind, this study aimed to explore intersectoral coordination and their participation in the integration of indigenous knowledge into adult education. In doing so, a qualitative research approach and a case-study design were employed. The study sample was composed of adult education experts and coordinators. Data was obtained through interviews, FGD, and document analysis. Furthermore, thematic analysis was the centre of this study data analysis. As a result, the study finding revealed that stakeholders' coordinated effort has been observed that lacks consistency in supporting indigenous-based adult education programs due to their deprived collaboration and the presence of not functional administrative structure. This makes the provision and the integration of indigenous-based knowledge systems into adult education sporadic in its coverage of indigenous learning contents and experiences.
\end{abstract}

\section{Introduction}

Indigenous knowledge (hereafter, IK) is a unique body of knowledge developed over time and continues to develop through generations living in close contact with nature and inhabitants $[1,2]$. The local community can use their ideas and beliefs in another way of knowing nature, which contributes to a better understanding of the social, cultural, economic, political, and natural aspects of local environments [3]. Local areas' knowledge is considered not only as of the high-quality competitive power but also as the social capital of the marginalized people in their struggle for survival $[4,5]$. That is why IK is generated by societal members as they seek solutions to their daily problems based on existing societal wisdom, other local resources, and a sense of creativity [6]. Due to this fact, significant contributions to global knowledge have originated from indigenous people and nature [7]. The emergence of inclusive education has demonstrated its relevance in meeting the needs of every learner irrespective of geographical, race, gender, and ability difference [7]. Therefore, indigenous perspectives are relevant to adult education (hereafter, $\mathrm{AE}$ ) programs as a way to explicitly address the social injustices committed towards indigenous peoples and as a form of epistemic and restorative justice for indigenous peoples $[8,9]$.

The integration of IK into AE needs strong collaboration based on recognizing indigenous frameworks and methodologies to give more attention to local people's history, politics, cultural beliefs, and philosophical views $[3,7,8]$. Hence, many education providers and actors are most likely to be successful in integrating indigenous perspectives into their curricula when they structure their programs guided by the local community and its knowledge holders [9]. 
However, in many parts of the world, previous study findings emphasized that indigenous education has greatly influenced the need for the development of a more appropriate problem-solving educational curriculum, policies, practices, and promotion of life-long education [7]. Likewise, current educational priorities are hopelessly misplaced, inadequate for the task of preparing adult learners for responsible, and active citizenship due to too much emphasis on science than trust and value their knowledge, skills, values, and experiences [10]. See specifically, previously, Ethiopia with the assistance of international development and education partners excluded the indigenous cultural knowledge from school education and adopted an (imported) nonhomely foreign system of education in the name of modernization [4]. Hence, as pioneered by Bewer et al. [9], educational administrators, curriculum developers, and educators as concerned representatives of $\mathrm{AE}$ providers must be mindful of how IK is treading through AE program provision.

As far as the researcher knows how concerned, beforehand, many studies have been conducted in Ethiopia focusing on scrutinizing IK and AE practice. For instance, many researchers [11-19] investigated the current practice of AE provisions across the context of policy and strategies, personnel such as AE experts and facilitators, learners' learning needs, and their participation, government, and other stakeholder roles in the program. Although AE practices have been extensively studied, most of the above-mentioned studies did not address how concerned stakeholders' collaboration and their involvement look like towards the inclusion of IK into the AE programs.

Furthermore, when the researcher discussed with experts from North Wollo [hereafter, NW) zone education, culture, and tourism departments, intersectoral participation towards the provision of indigenous-based $\mathrm{AE}$ remains symbolic due to obstructive factors. Likewise, Assefa $[8,13]$ in his study entitled Integration of IK into Adult Learning Material Development and the Facilitation Methodology suggested that "the implementation of indigenous-based AE has been seen by some stakeholders as their secondary task despite it demanding a collective effort. Hence, exploring the established intersectoral collaboration towards integrating IK into AE is needed." Considering this in mind, the researcher has initiated to explore in-depth the collaboration efforts made by stakeholders towards IK integration into the AE programs. In this sense, the researcher kindly informed the audience that this study is the extension work of Assefa's [8] suggestion as mentioned above. To uphold the direction of this study, the following basic research questions were forwarded. They are as follows:

(i) How has AE stakeholders' coordination structure been established? Does it contribute enough to their participation and be responsive to the integration of IK into AE programs?

(ii) How do concerned stakeholders promote and mainstream the integration of IK into AE programs to practice?

\section{Theoretical Framework}

AE is offered in an organized condition in the way that it can be provided by the government, nongovernmental organizations, and other voluntaries [20]. Similarly, the management and provision of IK require the involvement of several stakeholders and the entire local society. Usually, this knowledge may be held and managed under the responsibility of some social groups, such as tribes and specialists [21]. The engagement of both participants and local institutions to promote IK with initial transformative learning experiences demonstrates the potential for creating a path of critical consciousness [22]. More commonly, community engagement approaches use community members at the centre of the process to empower indigenous voices, strengthen community capacity, and promote meaningful change [23]. Educational communities and their actors, therefore, are encouraged to use their professional judgment and to reprogram educational content in terms of its scope, sequence, progression, continuity, and approach to teaching and evaluating [24].

In many contexts, local community leaders and elders are the guardians of IK [8]. Therefore, the participation of leaders in the development process of IK is vital to use for sustainable education and development [4]. Government, academics, conservationists, and NGOs working in various communities where IK systems hold great potential must coordinate with the local leaders and elders to use them in their intervention and education programs $[25,26]$. State authorities and their policies construct and reproduce knowledge claims or epistemic privileges in the provision of integrated AE. This, in turn, maintains the status quo that consistently promotes the lived experiences of indigenous communities [27]. Given the diversity of indigenous people, there is no single strategy for intertwining indigenous perspectives into education [9]. The local context must always be situated, contextualized, and appreciated.

Austin and Hickey [28] pointed out that any successful AE curriculum innovation that included the IK system and practice of the local community requires a combined effort of interested, informed, and committed parties. Typically, these parties include various sectors of the teaching profession (teachers, school administrators, and professional associations), curriculum development and promulgation agencies (governmental education institutions), professional development providers (both for preservice and for in-service professional development), and members of the broader community. Likewise, Bewer et al. [9] remarked on the necessity of AE stakeholders using elders, influential individuals, and families as other common principles of indigenous learning. Furthermore, they demonstrated the following:

...through our families, peers, and communities, we come to learn about ourselves through our ecology, land, and environments. Our Elders and families share their knowledge of the place in their daily personal and communal adventures on the land, in traditional tales, timed with the seasons, and in the context of everyday life. 
We come to know ourselves in a place, and by its depth of beauty, abundance, and gifts, we learn to respect and honour that place. All indigenous peoples have, then, a land base and ecology from which they have learned, and it is there that they honour the spirit of that land in ceremonies, traditions, prayers, customs, and beliefs. These, then, are the core foundations of indigenous knowledge, learned within language and culture (p:17).

Additionally, other scholars such as Naamwintome and Millar [29] forwarded supplementary strategies used by concerned stakeholders to connect IK to AE provision and address shortcomings in our knowledge systems. They mentioned the requirements of (1) going back to our roots, deschool, and preschool ourselves; (2) being proud of the locality and documenting the cosmovision-based knowledge and making it known that it is not static; (3) developing a system of knowledge generation and dissemination that incorporates people's spirituality as well as developing our oral tradition; (4) enrolling traditional institutions and helping to reconstruct knowing systems, teaching, and apprenticeship; (5) developing systems of investigation that will enable to better understand and deepen understanding about what the so-called secrecy of knowledge; (6) involving local as concerned in the knowledge development processes; and (7) revitalizing indigenous forms and systems of learning through integrating them into formal and/or none formal AE system.

\section{Methods}

This study is targeted at the NW administrative zone, found in the northeast part of Ethiopia. In conducting this study, a qualitative research approach suggested by Creswell [30] was employed. Besides, since the attention of this inquiry focused on exploring an in-depth investigation of intersectoral collaboration, involvement, and participation towards the integration of IK into AE programs, a case study research design pioneered by [30] would be the most appropriate. The data sources of this study are AE experts and coordinators who are directly involved in the provision of $\mathrm{AE}$ in the area. Hence, sample participants were carefully chosen from the NW zone education department (three AE experts and thirteen AE coordinators for interview) and NW culture and Tourism department (ten participants). A total of twenty-six participants were drawn by using purposive sampling techniques. This sampling technique is favoured because the focus of the sampling in this study is to find definite target groups who either hold practical know-how about the phenomenon (stakeholders, AE, IK) being studied rather than to represent the study population.

To obtain relevant data, the methods of data gathering tools and procedures used by Assefa [8] were employed because (1) the target and nature of data sources are similar and (2) this study is the extension work of the indicated author. With this in mind, data were obtained from respondents through interviews, FGD, and document analysis. Furthermore, a semistructured key interview was administered for AE experts and coordinators. The key interview issues were defined and arranged in the form of an interview guideline which helps to guide the focus as well as the direction of discussion with the interviewees. Procedurally, the discussion with each interviewee and focus group lasted between 45 and 60 minutes. The discussions with respondents were semistructured around themes. Clarification on some questions was enhanced through probing and prodding during meetings. Respondents' opinion was captured through audio recording and transcript verbatim. Additionally, documented data such as Ethiopian Ministry of Education (hereafter, MoE) AE related guidelines and NW $\mathrm{AE}$ progress and performance reports were considered to match the primary sourced data. During gathering data and its reporting, all respondents' confidentiality was protected using anonymity codes which represent study participants indirectly. Their name was coded, for instance, AE experts as $\mathrm{E} 1, \mathrm{E} 2$, and $\mathrm{E} 3$ and $\mathrm{AE}$ coordinators as $\mathrm{C} 1, \mathrm{C} 2, \ldots$ and $\mathrm{C} 13$; opinions of FGD discussants were pronounced as FGD1.

It is claimed that disclosing the methods of data analysis with enough detail enables the reader to determine whether the process is credible [31]. Hence, thematic analysis was employed as a major technique for analysing the data and interpreting the results of this study [30-32]. In doing so, the collected data were considered through coding and a detailed description of the case under the theme. To make sense of the multifaceted data, a consecutive explanation of the data was done during and after data collection. Then, a thorough clarification and interpretation of dominant case events emerged. After the description, the researcher gave thoughtful attention to a few problems for investigation of the complexity of the cases. Finally, as suggested by [30] and inspired by the method used by Assefa [8], issues within each case and then looking for common themes were established. In addition, to enhance readers an easy understanding of this study findings, the researcher tried to present the results through a chronological report of each case under themes and subthemes. Furthermore, the researcher associated the study findings with evidences in the available literature.

\section{Results}

Concerned stakeholders' collaboration and their efforts have priceless value in promoting and transferring IK from generation to generation through $\mathrm{AE}$ programs. This demands sound AE administrative structure, which emphasizes each stakeholders' effort played in towards the integration of IK systems and practices into AE. The study uncovered how the practice has been done in NW. In doing so, the findings were presented and categorised under themes and subthemes. The details are displayed in the following.

4.1. AE Stakeholders Coordination Structure. In moving forward, the provision of AE must be built into a holistic intersectoral approach that necessitates working together among concerned actors. The collaboration must be guided by the current and sustainable need for thoughtful partnerships, because the development of a holistic 
indigenous-based adult learning system and the application of AE demands structuring connections among diverse performers, organizations, progression, learning centres, local communities, and indigenous adult learners.

Consecutive establishment of the $\mathrm{AE}$ strategies and guidelines, especially the National Adult Education Strategy of Ethiopia, has given high recognition for concerned stakeholders' involvement to consolidate and sustain the AE program starting from the national to the grassroots level $[33,34]$. Through this decentralization, documented evidence of NW education department and all interviewed experts confirmed that the NW administrative zone intersectoral departments established AE administrative structure composed of six governmental office departments, such as Education Office, Agriculture Office, Health Office, Women and Children Affair Office, Finance and Economy Cooperation Office, and Technique and Vocational Training Office (hereafter, stakeholders). They had signed a Memorandum of Understanding and formed two major committees, namely, the AE Board and the AE technique committee to perform the AE program through collective effort.

Adult education in NW, like many other educational programs, is disposed to follow two typical administrative structures, such as the $\mathrm{AE}$ board and the AE technical committee. These two structures have their duties and responsibilities. As the detail is displayed in Figure 1, the AE board is represented by heads or vice heads of each department. Also, the AE technique committee is represented by one focal person who has a close profession with AE.

It has a definite hierarchy and clear boundaries as to which concerned stakeholders' heads and professionals are responsible for numerous tasks involved in indigenousbased adult learning operations. The organizational structure of the AE provider outlines who reports to whom and who is responsible for what. It often involves members of the AE administration and licensed and unlicensed support staff and teachers. From discussion with FGD1, E1, and E2, it can be outlined that these two teams are established expecting that they handle management and follow up schoolwide decisions, sometimes after consulting with AE facilitators and other concerned members. The administrative team especially concerned for the AE board is responsible for producing and endorsing policies, rules, procedures, and the required indigenous learning curriculum. Moreover, E1 revealed that even though the established administrative and technical pecking order of AE take several things into account when selecting an administrative structure, three major considerations, such as proper communication channel, authority, and span of control, were missed among stakeholders. This is due to topmost $\mathrm{AE}$ administrators deciding inadequately which stakeholder personnel had better oversee various AE tasks. As a result, the integration of indigenous-based learning into $\mathrm{AE}$ becomes deficient at this time.

4.2. Level of Selected Stakeholders Participation. To explore stakeholders' collaboration and each stakeholder's contribution to their participation and be responsive to the integration of IK into AE programs, the study respondents obtained from the NW zone education, culture, and tourism departments were asked to state the greatness of these stakeholders' involvement and their contribution towards the integration of IK into AE program delivery. The following are the details.

4.2.1. Education Sector. Need responsive based educational delivery enables indigenous adult learners to exercise and adore economic, personal, social, and cultural rights. It also reinforces their ability to exercise their civil rights so they can influence political policy processes for heightened fortification of their human rights. Education is, therefore, a vital means for the enjoyment, maintenance, and transmission of indigenous cultures, languages, traditions, and traditional knowledge, as well as a vehicle for individual empowerment and agency. Hence, the contribution of the education sector office and personnel to the AE delivery is likely to allow adult learners to enhance their IK through integrating into basic literacy and numeracy skills, such as reading, writing, and arithmetic.

Adult learners can grow their basic literacy skills when large numbers of $\mathrm{AE}$ facilitators/educators are obtained from the education sector. Despite the education sector participation in the AE program being crucial, respondents (E1 and E3) confirmed that sometimes their effort looks unsystematic and disorganized. The office assigned AE coordinators and facilitators to facilitate indigenous-based adult learning at the grassroots level at literacy centres. However, there is a high turnover of facilitators due to low compensation, and this practice makes the task only ideal. Additionally, meeting with FGD2 and FGD3 showed that beforehand within the Ethiopian education systems and policy, IK-based learning are recognized not simply as a benchmark of learning but simply imported from abroad. In this sense, adult learners do not participate in decisions that affect them, including the right to education on their terms and in line with their values, priorities, and needs. These education systems, policies, and curricula are rarely developed with indigenous peoples' participation or consent and, as a result, have mostly failed indigenous learners and stripped them from vital life opportunities. Given the importance of $\mathrm{AE}$ to the adult learners personal and social development, education administrators and managers must consider the well-being of indigenous learners and their traditional IK about their lands when interconnecting indigenous people to education, where elders pass down knowledge, values, and their histories to new generations. The education sector with other concerned stakeholders also should reconsider that culturally appropriate education systems are administered by indigenous peoples. This will, therefore, strengthen livelihoods and improve the cultural, community, and individual resilience and well-being.

4.2.2. Agriculture Sector. Agricultural education goes beyond knowledge and skills development that adult learners can develop an understanding of (1) the significance of agriculture through the application of new business 


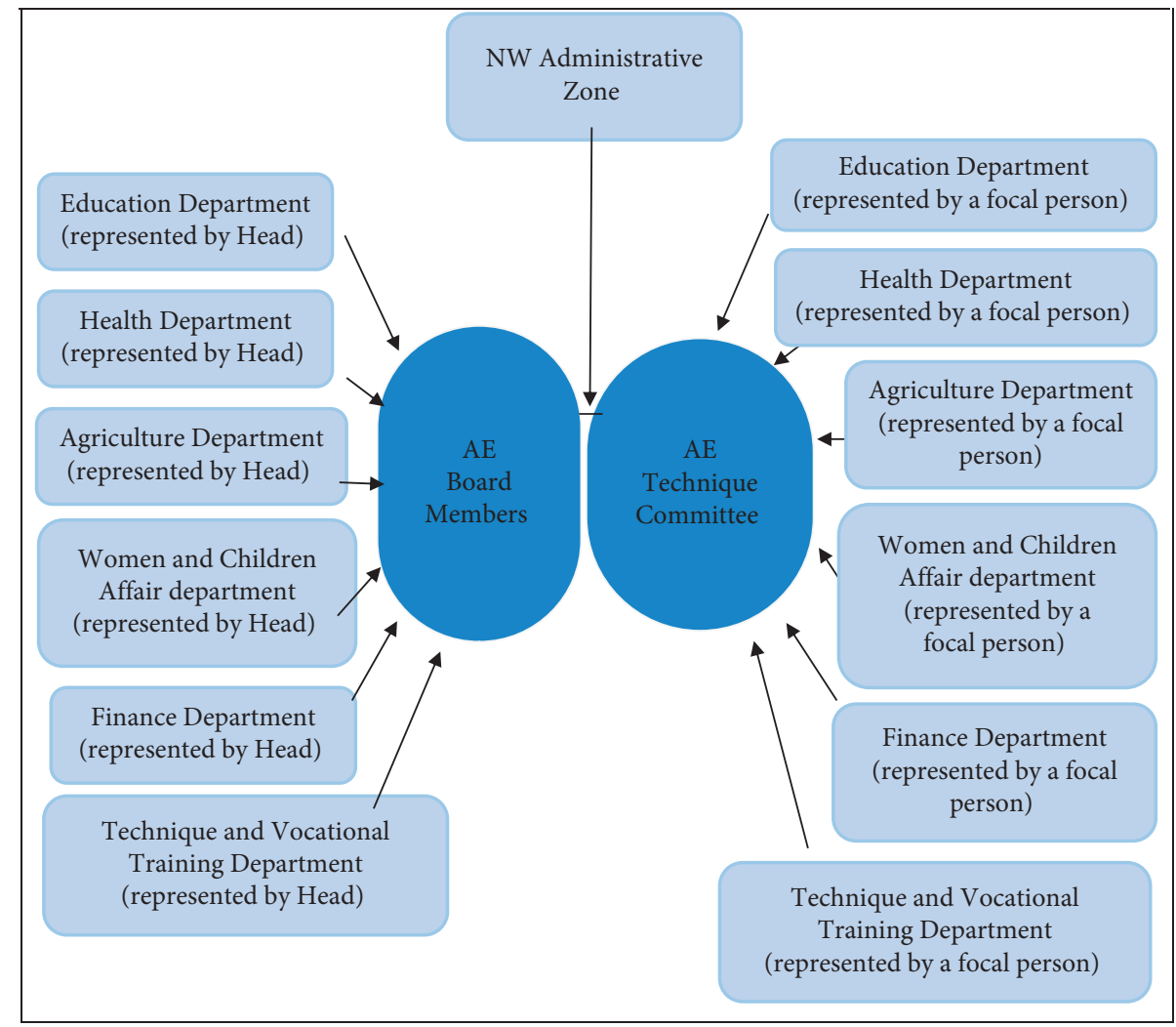

FIgURE 1: NW zone AE administration structure.

principles and problem-solving strategies within what they have known so far and (2) the interdependency between the agricultural activity and other significant occupational activities intertwined with the entire economic and social structure of the community. Considering this agriculture office and personnel has been included in the AE administrative structure that emphasizes educating adult learners about the rural and urban agricultural extension packages based on environmental ecology, environmental issues, and development of life skills.

The role of the agriculture sector is expected to have more contribution than others. In the area, many indigenous farming practices could be scaled up to the mass through integrating indigenous agricultural education and practices into AE programs. The office has a good practice of educating adult farmers within their locality about agricultural extension packages (E2 and FGD1). However, meeting with AE coordinators ( $\mathrm{C} 2, \mathrm{C} 3$, and $\mathrm{C} 5)$, it can be understood that although the involvement of the agriculture office is good, sometimes lower-level experts segregate farmers IK systems and practices from farming education. In this sense, educationally, agricultural agents/educators see themselves as knowledge givers and their adult learners-farmers as simple receivers. On the contrary, it is the fact that teachers in agricultural education must regard adult learners as mature and have a package of experience accumulated over time who merit individual kindness and who work in a lifeoriented environment. Considering the above in mind, concerned administrators and personnel from the agriculture sector should contemplate that agricultural education offers many prospects for indigenous adults to learn basic agricultural skills and knowledge through (1) working with other stakeholders in the area such as farmer training centres, community villages, and alternative basic education institutions and (2) integrating those learning contents into learner's prior knowledge.

4.2.3. Health Sector. Regarding health sector participation, literacy is often a factor in health issues, predominantly precautionary health. Its involvement assists in discourse between the foremost global and local health problems with the lowest cost. Having had several existing indigenous systems of medication, the role that these systems play in the NW is great. The area's foremost health problem includes communicable disease, environmental sanitation, nutritional disorders, child care, and so on. Most people use traditional indigenous medicine to get healed (E3). Most of the respondents $(\mathrm{E} 1, \mathrm{E} 2, \mathrm{C} 1, \mathrm{C} 2$, and $\mathrm{C} 7)$ uncovered that health sector participation in $\mathrm{AE}$ had supposed benefits to advance the adults' healthy life and lessen their costs that possibly will be paid for medication. Nevertheless, the practice looks far from wished for. This result shows that the health sector has a low level of involvement in the program implementation. They did not adequately consider the issue of $\mathrm{AE}$ as their routine task; rather they see it as their secondary responsibility.

Furthermore, FGD1 remarked that with little consideration of traditional medicine, the present system of health education is vertically structured and delivered by only what 
we called modern health institutions that impart knowledge in their disciplines and impose it to the community. They did not use other sectors such as education, agriculture, and others as a supportive agent to outreach their service to the mass community. If the indigenous systems of healing services could be incorporated into the existing AE system, it would undoubtedly achieve worthwhile results. Bearing in mind the drawbacks of modem medicines and the inability of indigenous medicines to exist on their own, there is a need to integrate all the forms of medicine under a single umbrella by strengthening the role played and participation of the health departments within the AE administrative structure.

4.2.4. Other Sectors. Besides, near to all respondents pronounced that the extent of other sector offices, such as women and children affairs office, finance and economy cooperation office, and technique and vocational training office, was found in the ground. From this result, anybody can understand that even though such concerned stakeholders had signed the Memorandum of Understanding, which aims to enhance indigenous-based AE program in a collective effort, their involvement and contribution were found very low.

In general, indigenous-based designed $\mathrm{AE}$ have a lot to contribute to a higher personal and social development. Hence, designing an indigenous-based program for adult learners can be quite different from doing the same for a typical program. When designing AE programs that are appropriate for adult learners, stakeholders and administrators should establish their collaboration structure aimed at purely integrating IK into AE program deliveries. Also, when establishing collaboration, keeping at least the following five things, it is very important to say that stakeholders' collaboration and their contribution to their participation are responsive for adult learners (accessed from https://evolllution.com/programming/program_pl anning/retrieved on 15 Dec. 2021). These are as follows. (1) Consider Adult Learners' Life Experience. Adult learners have life skills and experiences that are reflected in their coursework and what they expect from their programs. Because of their experiences, they often have much to contribute to adult learning, as well as specific topics and ideas they want to pursue in their studies stemming from these life experiences. (2) Recognize Adults as Active Learners. Adult learners are rarely passive learners; they tend to work hard in and out of class. Because most adult learners are funding their education or studying with financial support from their employers, they have a vested interest in succeeding. (3) Develop Flexible Schedules. The program must be flexible for the adult learner to be successful. Many adult learners work full time and often during the day; hence, they prefer programs that offer courses in the evenings and on weekends. (4) Consider Adults Having Academic Inexperience. Adult learners are often worried or apprehensive about going back to school, since many have been out of school for a long time; however, they are typically very successful, as they are highly motivated and self-directed. (5) Appreciate Learners' Wisdom. Adult learners should be respected for the life and career experiences they bring to the classroom. An instructor who approaches a class of adult learners with the view of having an equal opportunity to learn will be the most successful. The instructor already has mastery of the subject, but he or she can often learn from the discussion, research, and projects the adult learner completes during the course.

4.3. Mainstreaming IK in AE Program. Stakeholders' participation in $\mathrm{AE}$ is irreplaceable and enables them to make accurate and tangible decisions about the program [13, 17]. Concerned stakeholders' role in their sectors has a great influence in enhancing indigenous-based knowledge to the mass. One of the most important beginning phases and tasks in promoting IK-based learning is to identify and agree on what roles and responsibilities are played by all concerned stakeholders. Therefore, differentiating roles and responsibilities with accomplishment strategies must be a kick-off task for all $\mathrm{AE}$ administrators and professionals. If it is so, discharging of responsibilities is available and thereby the right task is assigned to the right implementers. To make it more understandable, the status of undertaking strategies used by concerned stakeholders as a means of promoting and mainstreaming IK within AE programs in NW has been presented here below under five subthemes.

4.3.1. Engaging Local Communities to Develop and Preserve $I K$. Participation of the local community in the provision of the $\mathrm{AE}$ is crucial for both the success of the collaboration and the achievement of the overall objective of the program [17]. Two dominant themes related to community engagement such as adapting to a cultural context and inclusion of community outreach [23] can be used within a specific program provision, especially in IK-based on AE delivery. Therefore, engaging the local community in the process of their learning is the groundwork for any stakeholders. However, it is observed that concerned sectors following up how parents teach their children, craftsmen teach novices, elders guide young individuals, and youngsters undertaking instigation rituals were found unsatisfactory level $(\mathrm{C} 1, \mathrm{C} 2$, C4, and C6). This practice in turn tells unless we empower and actively participate the local people in $\mathrm{AE}$ provision activities, it is hard to share and sustain indigenous-oriented learning for young generations within the community. Community participation through their family, social gatherings, and other kinds of associations contribute more to enhancing intergenerational learning, which is necessary for IK advancement. Similarly, previous studies revealed that the lack of methodological guidelines used by stakeholders to enhance community engagement will contribute to the fall achieving local community learning needs [23].

4.3.2. Working with Indigenous Organizations and Social Gatherings. IK learning material contains a variety of learning contents and experiences drawn from adult learners in which they want to learn practically and theoretically. The kind of learning materials, in this case, must be inclusive 
because all learners have their prior knowledge that needs enough consideration. The only tool for integration is therefore developing learning materials through the participation of all concerned stakeholders and local community institutions. The area, NW, is full of indigenous organizations, social gatherings and institutions such as Mahiber (religious groups), Idir (local association organized by the guild), and Ikub (local loan and saving association), established for group work in socioeconomic activities. These local organizations are vital to share resources, manpower, and technology and exchange information, and also it can be used as a resource for the provision of IK-based AE. During a discussion with FGD1, it was pronounced that "institution and social gathering participation is limited not only in designing learning materials but also in participating in the learning programs. Most of the time, this task saw only the government role as a short-term campaign and a secondary role for other stakeholders." Likewise, in an interview with coordinators, it can be summarized that the practice of inviting the local community and their gatherings during indigenous adult learning material development and validation has been forgotten. Only some selected experts at the centre developed and endorsed it (C1, C3, C4, and C6). This makes AE provision sporadic and has limitations in its indigenous learning content coverage. Narrow emphasis is given to connecting their memories and spiritualities with their learning due to the availability of inadequate local institution involvement.

Discussion with E1, E2, and FGD1 remarked that the NW community has a high demand for indigenous education, which are driven by their locality. However, it is unable to deliver effectively due to many constraints, such as lack of human resources, which are well-trained facilitators. Using local organizations and social gatherings can help to set a bridge into the existing gap through communicating and exchanging indigenous-based knowledge and skills with the wide community. Discussion with respondents revealed that although stakeholders have many opportunities of working with and taking experience from existing local organizations and social gatherings, creating discussion forums to discourse and share knowledge is minimal (E2 and FGD1). Especially the role played by zone culture and tourism department was found a little bit concerning. This practice demands working with available social gatherings and small groups that include farmer associations, religious associations, and other work-related groups, which enables to identify miscellaneous problems that faced the integration of IK.

\subsubsection{Making Advocacy and Supply Resources to Strengthen} Local People IK Adaptation to Local Development. Raising public awareness about IK contribution to local development must become the first concerning task when advocating it to the masses. At the same time, communitybased awareness raising about the relevance of IK-oriented education must be done at the beginning to enhance the positive inclusion of IK into local development initiatives. Surprisingly, in an interview meeting with the AE expert
(E1), he commented that nothing is done in the area. Shortterm seasonal mobilization per year is made to activate the community to participate in AE programs. However, sustaining and connecting this advocacy with IK systems and practice have been missed.

Although there are many endorsed policies and strategies [34-41] developed to support educational practices, and particularly the AE sector development, none of them could advocate the positive value of IK for the local area's development. Under such policy and strategies, stakeholders could motivate local people adaptation to available IK, such as knowledge of traditional medicine, beauty management, traditional conflict management, socioeconomic practices, and others to adapt such knowledge for local development. To confirm this, it can be summarized from participants' (C1, C3, C4, C5, and C7) responses that an in-depth background study is conducted about the existing IK systems and their practice being needed before advocating educational and other local development policies and strategies. This is not done due to resource constraints such as shortage of expertise and budget, as a result, being unable to know and outreach the extent of each available IK system and practice in NW.

\subsubsection{Documenting IK Systems and Practices. Documentation} can be considered invaluable means of protecting and transferring IK systems from one generation to the next. In most of the interviews and FDG sessions, it has been established that this practice was found on the ground. Especially, FGD1, E1, E2, C1, and C3 marked that although many pearls of wisdom owned by a few persons are available in their locality, their nature and practices are not well known and documented by any means. Hence, literacy centres, local museums, libraries, memorial places, and social gatherings as a concerned stakeholder must contemplate IK as a contemporary body of knowledge in the field of AE. IK may perhaps be documented and stored in the form of communicative texts (reports, books, and maps), audiovisuals (photos, films, videos, or audio cassettes), and artworks (stories, songs, drawings, seasonal patterns charts, and daily calendars). These strategies accelerate IK transferability for the next generation.

Most importantly, two kinds of IK practice were documented well in NW. For instance, documentation of spiritual healing services has been made by religious institutions (especially, the Ethiopian Orthodox Church in which most of the spiritual healing services are owned and practiced by the Church). Additionally, traditional conflict resolution and reconciliation systems, such as Sheh lega, Zeweld, and Aba gar (practiced in Muslim populated areas), were registered and recognized by Amhara Regional General Attorney Bureau (sourced from NW Culture and Tourism unpublished magazine, 2008). On the other hand, from respondents (FGD1), it can be concise that initiation has been available for preparing inventories and registering traditional IK systems found in different parts of NW. However, the lack of expertise personnel makes the beginning unsustainable. Expertise is available only at the 
Centre Zone Culture and Tourism Department. No one is placed at the grassroots level in the community who document and register all kinds of IK practices. The inventory problem resulted from a deficiency of capacity and funds that make the documentation process difficult. This indicates the task is neglected especially by governmental stakeholders. As a result, documenting and developing standardized tools for indexing and cataloguing IK and taking into account the intellectual property implications of such inventories and registries were found to unsatisfactory levels in the area.

4.3.5. Disseminating IK Information. No shortage of arguments strongly supports the claim of IK, which is generated, transformed, and disseminated through a systematic process of observation, experimentation, and adaptation [42]. IK system dissemination can be undertaken through publications, conferences, workshops, and social gathering targets at uncovering grassroot level practices. Even though limitations are existing, improvements have been observed where the NW Culture and Tourism Department tries to disseminate IK information using local available media in collaboration with broadcasting institutions (via Woldia University FM and Amhara Media corporation), the publication (in print and electronic format), and conference proceedings (FGD1, C4, and $\mathrm{C} 6$ ). IK dissemination in AE programs can be considered as the collaborative process of communicating knowledge for targeted adult learners to bring a contextual positive change. However, the challenge in the area is explained by little effort that has been made to build a local capacity for sharing IK in $\mathrm{AE}$ due to deficiencies in disseminating strategies (E1 and E2). Also, concerned stakeholders neglected the development of IK practice sources and partnership database formation. To progress, the availability of outreached knowledge systems to beneficiaries of those they are envisioned to reach must go through diverse mechanisms.

\section{Discussion}

The AE implementation guidelines of Ethiopia clearly articulated the relevance of stakeholders involved in collaboration towards the provision of indigenous-based $\mathrm{AE}$ programs [33, 34]. Effective IK-based AE requires great synergy between policies and practices that consider the local context and active participation of the community $[8,13,17]$. However, in practice, this study finding demonstrated poor engagement of local communities to support the development of IK-based education using deliberate instruction in AE provision activities. Even though national, regional, and international declarations and commitments have recognized the importance of collaboration between/ among stakeholders in the provision of $\mathrm{AE}$ [33], the established collaboration among these sectors to support IKbased $\mathrm{AE}$ was found unsatisfactory. The established administrative structure by concerned stakeholders passes many ups and downs, and it lacks consistency. Moreover, the provision of AE was considered the sole responsibility of the MoE and its subsidiary offices.

Indigenous wisdom and learning are crucial elements when considering the inclusion of IK within any kind of educational setting based on considering the importance of indigenous values, culture, tradition, and languages [9]. In the strategy document of MoE, the government acknowledged that $\mathrm{AE}$ program implementation and achieving its objectives require collaborative efforts and the contributions of different stakeholders [33]. However, previous studies in the field portraited that efforts were uncoordinated and disregarded $[8,13,17,33]$. Likewise, this study finding shows most stakeholders overlooked indigenous-based AE as their secondary role and responsibility.

Putting for discussion continuously can help stakeholders to compromise their difference on their consideration of IK and AE. This demands the local government to create a common understanding for all actors to consider IK as a foundation of their work. In doing this course of action, minimizing threats arising from communities (e.g., individuals who know traditional medicine fear that their knowhow will be taken illegally by others) and doing sustainable awareness-raising activities brings adult learners and the community at wide having a broader understanding of IKbased learning. Also, delivering continuous training for $\mathrm{AE}$ facilitators and learning material developers and endorsing inclusive memorandum of understanding through the participation of all stakeholders can help them to balance IKbased assistance. Hence, as suggested by scholars, mobilizing community's social gatherings, local associations, education providers, and local government engagement for the design and implementation of an educational intervention serve as a source of support and action taken to improve educational provisions [23].

Many local organizations and social gatherings have their role in the community available in the area aim at enhancing people's educational and social development. They can be considered as a resource for enhancing IK integration into $\mathrm{AE}$ if a sound working environment is created. However, this study finding uncovered promoting local community institutions in designing IK-oriented adult learning materials and working with indigenous local organizations and social gatherings to make IK accessible for learners, which were found unsatisfactory. This practice also creates an advantage-based interrelationship between local government and social organizations, which becomes a problem to preserve and integrate IK into any form of educational program. Similar study findings discussed by Samuel and Abebaw [17] revealed that participation in local community organizations and other social gatherings is not significantly well-known, mainly due to two reasons. First, the established collaborations failed to involve local community representatives (e.g., religious leaders, model families, and other influential individuals) as committee members. Second, enough efforts have not been made to enhance awareness of the local community regarding the program objective.

Whichever concerned sector, documentation and dissemination of IK systems and practices can be considered as 
other strategies of promoting indigenous-based education. Unfortunately, this study opens that although many pearls of wisdom owned by a few persons are available in the study area, its nature and practices are not well known and documented in any means due to lack of commitment of the concerned body and the resource constraints. It is thus essential to document the pearls of traditional knowledge systems [42].

\section{Conclusion}

The most important beginning phases and tasks in promoting IK-based learning are establishing a responsive administrative and governing structure that helps to identify and agree on what roles and responsibilities are played by stakeholders. Yet, stakeholders' effort has been observed that lacks consistency in supporting the indigenous-based $\mathrm{AE}$ program provision due to their poor collaboration. This makes the provision of IK-based AE sporadic in its coverage of indigenous learning contents and experience. Furthermore, the utilization of several strategies used by stakeholders to mainstream and promote indigenous-based AE is two-faced. The first is the area characterized as the availability of many local institutions interested in advocating IK in the provision of AE. The second is the lack of interest and capacity deficiency observed from the governmental stakeholders to use such local institutions as a supportive agent. However, the mainstreaming task must be fully appreciating and recognizing the engagement of the local community and their institutions in learning. It must be the groundwork for any stakeholders in the field. They can contribute more to enhance intergenerational learning, which is necessary for IK advancement. Most importantly, if stakeholders undertake context-based integration strategies for IK and AE, it will accelerate IK transferability for the next generation.

\section{Implication and Future Studies}

IK offers rich context for the provision of $\mathrm{AE}$ programs that have the potential to contribute to recognizing the relationship of environmental, sociocultural, and spiritual understandings of life and nature. Therefore, some governmental sectors such as agriculture, health, security, NGOs, and other concerned stakeholders working in the area may gain highlights from this study to incorporate local people's indigenous practices and thereby realize their planned tasks. Furthermore, the nature of IK is so broad and studying its integration into $\mathrm{AE}$ requires a large time, number of researchers, and resources. With these constraints in mind, the researcher bounded the study to explore concerned stakeholders' collaboration and how they mainstream the integration of IK systems and practice into AE program provisions in the NW zone. Hence, the researcher kindly informs the audience, including scholars, academicians, research institutions, and others concerned due to only space constraints, other issues of IK and $\mathrm{AE}$ practice that are not considered in this study, such as existing practical challenges, contextual considerations, and IK incorporation into indigenous policy and strategies, and related facts need to be explored.

\section{Data Availability}

Data are available at the corresponding author upon a reasonable request.

\section{Conflicts of Interest}

The author declares no conflicts of interest.

\section{References}

[1] C. Ezeanya-Esiobu, "Indigenous knowledge and education in africa," in Indigenous Knowledge and Education in AfricaSpringer Nature Pte Ltd, Berlin, Germany, 2019.

[2] M. Tufa and F. M. Gebremariam, "The role of indigenous healing practices in environmental protection among the maccaa oromo of ilu abbaa," Social Sciences and Education Research Review, vol. 4, no. 1, pp. 30-53, 2017.

[3] R. Zidny, J. Sjöström, and I. Eilks, "A multi-perspective reflection on how indigenous knowledge and related ideas can improve science education for sustainability," Science \& Education, vol. 29, no. 1, pp. 145-185, 2020.

[4] T. Abera, "Indigenous knowledge for sustainability education in Ethiopia," IMPACT: International Journal of Research in Humanities, Arts and Literature, vol. 8, no. 1, pp. 39-48, 2020.

[5] J. Hamilton-Ekeke and E. Dorgu, "Curriculum and indigenous education for technological advancement," British Journal of Education, vol. 3, no. 11, pp. 32-39, 2015.

[6] M. Mawere, "Indigenous knowledge and public education in Sub-Saharan Africa," Africa Spectrum, vol. 50, no. 2, pp. 57-71, 2015.

[7] T. E. Lukong, "Indigenous peoples education: priorities for inclusive education, the case of Cameroon," International Journal of Human-Computer Studies, vol. 2, no. 3, pp. 17-27, 2016.

[8] Y. Assefa, "Integration of indigenous knowledge into adult learning material development and the facilitation methodology," Educational Research International, vol. 2021, Article ID 2231759, 10 pages, 2021.

[9] V. Van Bewer, R. L. Woodgate, D. Martin, and F. Deer, “The importance and promise of integrating Indigenous knowledges in nursing education," Witness: The Canadian Journal of Critical Nursing Discourse, vol. 2, no. 1, pp. 11-24, 2020.

[10] D. Hodson, "Going beyond STS education: building a curriculum for sociopolitical activism," Canadian Journal of Science, Mathematics, and Technology Education, vol. 20, no. 4, pp. 592-622, 2021.

[11] M. Abiy, A. Roger, and Z. Turuwark, "Leaving the job half done? An analysis of mid-term withdrawals by facilitators in some adult literacy learning programs," International Journal of Educational Development, vol. 65, pp. 194-206, 2019.

[12] K. Ambissa, "Adult basic literacy "initiatives" in Ethiopia: change and continuity," Journal for Critical Education Policy Studies, vol. 12, no. 1, pp. 238-261, 2014.

[13] Y. Assefa, "Towards learner-oriented monitoring and evaluation in adult education program: a vital approach to ensure adult learners' learning needs," Educational Research International, vol. 2021, Article ID 6663700, 11 pages, 2021.

[14] W. Dessu, "Provision and participants of adult education: an overview," Adult Education and Development, vol. 22, no. 1, pp. 196-210, 2005. 
[15] G. Genet, "An assessment of Ethiopia's progress towards attaining integrated functional adult literacy," Bahir Dar Journal of Education, vol. 14, no. 2, pp. 14-28, 2014.

[16] D. Samuel, G. Gelana, and D. Mekonnen, "Developing a lifelong learning system in Ethiopia: contextual considerations and propositions," International Review of Education, vol. 60, no. 5, pp. 639-660, 2014.

[17] G. Samuel and Y. Abebaw, "Factors affecting intersectoral collaboration in the provision of adult education in Ethiopia," Studies in the Education of Adults, vol. 53, no. 1, pp. 42-60, 2021.

[18] B. Sandhaas, "Portrait adult education Ethiopia," Dvv International, vol. IX, p. 137, 2009.

[19] Z. Turuwark, A. Rogers, and N. Tolera, "Profiling adult literacy facilitators in development contexts: an ethnographic study in Ethiopia," International Review of Education, vol. 64, no. 1, pp. 9-30, 2018.

[20] M. Robso, "Where indigenous knowledge is beyond modernity: an experience from the Ethiopian orthodox church traditional adult education practices, Ethiopia," Palarch's Journal Of Archaeology Of Egypt/Egyptology, vol. 18, no. 1, pp. 4143-4160, 2021.

[21] S. Lodhi and I. Naseem, "The implication of indigenous knowledge management," IScience Series Data Report, vol. 4, no. 9, pp. 83-92, 2012.

[22] C. Kinzel, "Indigenous knowledge in early childhood education: building a nest for reconciliation," Journal of Childhood Studies, vol. 45, no. 1, pp. 19-32, 2020.

[23] S. Wali, S. Superina, A. Mashford-Pringle, H. Ross, and J. A. Cafazzo, "What do you mean by engagement?-evaluating the use of community engagement in the design and implementation of chronic disease-based interventions for Indigenous populations-scoping review," International Journal for Equity in Health, vol. 20, no. 1, pp. 1-20, 2021.

[24] F. Murillo, "The curriculum of the plague," Prospects, vol. 51, pp. 1-12, 2021.

[25] K. Adom, "Indigenous knowledge for environmental sustainability education in Ghana: Myths," Agriculture \& Food: E-Newsletter, vol. 1, no. 3, pp. 43-45, 2019.

[26] K. L. Thompson, T. C. Lantz, and N. C. Ban, "A review of indigenous knowledge and participation in environmental monitoring," Ecology and Society, vol. 25, no. 2, pp. 1-27, 2020.

[27] V. Anthony-Stevens, J. Jones, and V. Begay, "Regenerating teacher education programs with indigenous knowledge in Idaho," Northwest Journal of Teacher Education, vol. 15, no. 3, pp. 1-12, 2020.

[28] J. Austin and A. Hickey, "Incorporating indigenous knowledge into the curriculum: responses of science teacher educators," The International Journal of Science in Society, vol. 2, no. 4, pp. 139-152, 2011.

[29] B. A. Naamwintome and D. Millar, "Indigenous knowledge and the african way forward: challenges and opportunities," OALib, vol. 2, no. e1295, pp. 1-9, 2015.

[30] J. Creswell, Research Design: Qualitative, Quantitative, and Mixed Methods Approach, SAGE Publications, Thousand Oaks, CF, USA, 2018, http://library1.nida.ac.th/termpaper6/ sd/2554/19755.pdf.

[31] L. S. Nowell, J. M. Norris, D. E. White, and N. J. Moules, "Thematic analysis: striving to meet the trustworthiness criteria," International Journal of Qualitative Methods, vol. 16, no. 1, pp. 1-13, 2017.

[32] L. Cohen, L. Manion, and K. R. B. Morrison, Research Methods in Education, Routledge, England, UK, 6 edition, 2007.
[33] MoE, National Adult Education Strategy, Ministry of Education, Addis Ababa, Ethiopia, 2008a.

[34] MoE, National Report on the Development and State of the Art of Adult Learning and Education (ALE), MoE, Addis Ababa, Ethiopia, 2008b.

[35] MoE, Education and Training Policy, George Printing Press, Addis Ababa, Ethiopia, 1994.

[36] MoE, Education Sector Development Program I (ESDP-I), MoE, Addis Ababa, Ethiopia, 1998.

[37] MoE, Education Sector Development Program II (ESDP-II), Ministry of Education, Addis Ababa, Ethiopia, 2002.

[38] MoE, Education Sector Development Programme III (ESDPIII), Ministry of Education, Addis Ababa, Ethiopia, 2005.

[39] MoE, Education Sector Development Program IV (ESDP IV), Ministry of Education, Addis Ababa, Ethiopia, 2010.

[40] MoE, Education Sector Development Programme V (ESDP V), Ministry of Education, Addis Ababa, Ethiopia, 2015, http:// planipolis.iiep.unesco.org/sites/planipolis/files/ressources/ ethiopia_esdp_v.pdf.

[41] MoE, Ethiopian Education Development Roadmap (2018-30), Ministry of Education, Addis Ababa, Ethiopia, 2020, http:// planipolis.iiep.unesco.org/sites/planipolis/files/ressources/ ethiopia_education_development_roadmap_2018-2030.pdf.

[42] S. Singh and A. Saha, "Documentation of indigenous knowledge in the farming system," International Journal of Bio-Resource, Environment and Agricultural Sciences (IJBEAS), vol. 3, no. 2, pp. 548-553, 2017. 